\title{
A Simple Graphical Approach to Quantitative Monitoring of Rangelands
}

\section{By Corinna Riginos, Jeffrey E. Herrick, Siva R. Sundaresan, Cary Farley, and Jayne Belnap}

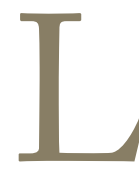

ong-term monitoring can provide the information that managers need to determine whether their current management program is meeting their objectives. Monitoring is also needed to compare management systems. However, it is often neglected because managers perceive data collection, analysis, and interpretation to be complicated or time-consuming. In this paper, we illustrate how a simple, graphical approach can be used to rapidly collect and summarize the basic data necessary to characterize vegetation cover, composition, height, spatial structure and density - all on a single sheet of paper.

Our approach to monitoring provides several advantages. First, it is technically simple. The only equipment needed for all four core methods are a stick or piece of pipe $1 \mathrm{~m}$ long, a pencil, and a single data sheet. All data for a site can be collected in 20-45 minutes, and monitoring indicators can be calculated by hand from that data in $<10$ minutes. The data sheet is almost entirely graphical, enabling rapid data recording. The completed sheet also provides a visual representation of the spatial pattern and structure of the vegetation at the site. In addition, the data are largely compatible with quantitative data collected for local $^{1}$ and national ${ }^{2}$ monitoring programs in the United States and elsewhere in the world.

The approach was recently developed to address the needs of rangeland managers in eastern Africa, where it has received strong, positive reviews from a wide variety of private and communal livestock managers and is now being formally adopted by nongovernmental organizations (NGOs) in Kenya, Tanzania, and Ethiopia. Recent discussions with rangeland professionals in the United States, Argentina, and Botswana suggest that this simple approach may be useful to rangeland managers throughout the world. Here, we describe the approach, discuss its strengths and limitations, and consider its potential application in rangelands globally.

\section{Background}

These methods were developed with the goal of providing a simple, systematic approach to ecological monitoring that could be used by a variety of land managers, including private ranchers, pastoralist communities, NGO staff, extension agents, private consultants, and park and land-conservancy managers. These methods were presented in a 100-page guidebook that provides a 10-step process for designing and carrying out a monitoring program. ${ }^{3}$ In developing the guidebook and methods, our objective was to make it as easy as possible for land managers to collect monitoring data they could use to evaluate the effects of their management and to adapt accordingly.

Most existing monitoring guides throughout the world have been written primarily for extension agents and consultants, ${ }^{4-6}$ sending the implicit message that ecological monitoring can only be carried out by university-educated technical experts. This has the unintended consequence of excluding from the monitoring process the people who actually manage the land. Most managers have limited time for complex monitoring systems. In many parts of the world, including eastern Africa, low levels of literacy and numeracy also make such systems impractical. More recently, there has been greater attention given to the potential and need for local knowledge-including, but not limited to traditional ecological knowledge - to be incorporated into rangeland monitoring and management programs. ${ }^{7-10}$

To ensure that our monitoring methods were in line with-and could be integrated with-local knowledge, we researched traditional indicators of ecosystem function and degradation used by various pastoralist groups in Kenya and Ethiopia, using published reports ${ }^{11-12}$ and informal interviews. Local indicators of negative change in rangeland function almost invariably fell into three categories: 1) increases in the amount of erosion being observed; 2) changes in plant species composition (including changes from dominance by grasses to dominance by small trees and shrubs, changes from dominance by perennial to annual grasses, and increases in native and non-native invasive succulents and shrubs); and 3) decreases in livestock productivity (including animal health and meat and milk yield). These indicators are virtually 
identical to indicators of negative change in rangeland ecosystem function that are cited around the world based on both scientific and traditional knowledge systems. ${ }^{8,10}$

Because our goal was to develop methods that could produce "early warning" indicators of long-term change (positive or negative) in rangeland ecosystem function, we focused on indicators of change in erosion potential and plant community, but not livestock production. Livestock production often responds slowly to changes in the land or may indicate short-term, rather than long-term, change. A decrease in a site's ability to withstand erosion, on the other hand, is a bellwether of degradation and loss of future plant and livestock production.

\section{Overview of Monitoring Methods}

We focus on four monitoring methods that can be used to generate a variety of indicators of rangeland ecosystem function. "Ecosystem function" has been defined in many ways. Here, we focus on three fundamental attributes ${ }^{13}: 1$ ) soil and site stability (limiting soil erosion), 2) hydrologic function (promoting infiltration and water storage capacity, and reducing runoff), and 3) biotic integrity (primarily promoting growth and reproduction of plants and maintaining a healthy plant community). These attributes are the foundation on which most ecosystem services-including livestock production, biodiversity, and wildlife conservation, provision of clean air and water, and watershed conservation-are based (Fig. 1).

The four monitoring methods together provide a set of indicators that are necessary to assess changes in land health for most common land management objectives. In many cases, the indicators generated from only two or three of these methods are sufficient for managers to assess their progress toward their management objectives.

The four methods are meant to be used along one or more transects, or at a series of microplots within a larger plot. The data sheet is designed around four 25-m-long transects, one in each compass direction (originating from a central starting point). The transects are established by pacing out $5 \mathrm{~m}$ between data collection points, rather than laying down a tape. At each point, the data collector lays down a 1-m-long stick approximately $50 \mathrm{~cm}$ in front of his/ her foot, perpendicular to the transect line, and collects data based on where this stick falls.

\section{Graphical Data Sheet}

Data for all four of the monitoring methods can be recorded on a single data sheet (Fig. 2). Each "stick location" is represented by a box in which the data are recorded. Most of the data are recorded by circling icons, marking a small box, or recording numbers. The data sheet is designed to be usable by somebody with minimal literacy, but in field trials many people with a high level of literacy found it faster and easier to use than a conventional data sheet. We have found that individuals with limited literacy and numeracy can also use changes in the pattern and density of marks on the data sheet to help document and interpret the patterns they

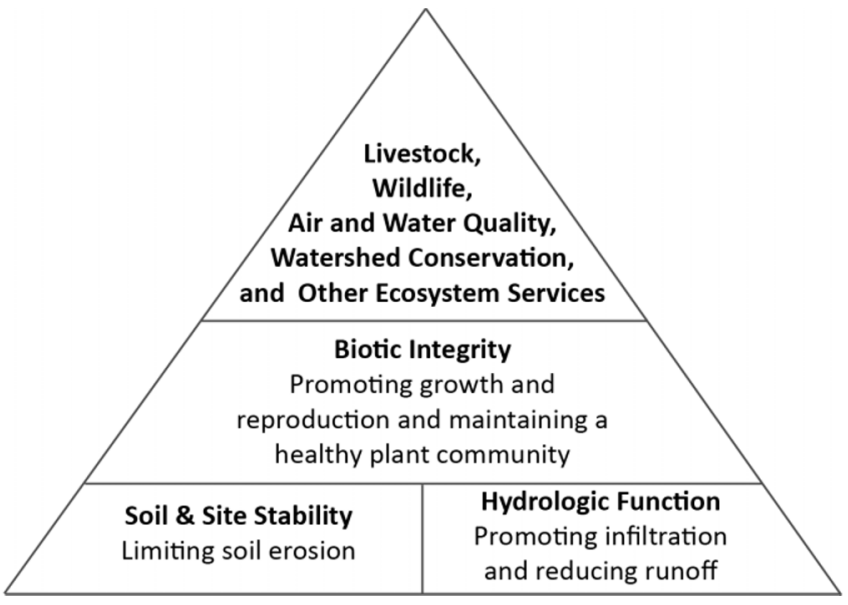

Figure 1. This approach to monitoring focuses on detecting critical changes in soil and site stability, water as it functions in the ecosystem, and perennial plant growth and reproduction. These three attributes form the foundation on which most ecosystem services rest.

observe. For example, in Figure 2, the high density of circled tree icons in the eastern and western quadrants reflect the high tree cover along these transects.

\section{Method 1: Plant and Ground Cover}

Indicators of plant and ground cover (the proportion of the ground covered by different types of plants, litter, or rock, as opposed to unprotected, bare ground) are central to most long-term monitoring systems. Plant and ground-cover data inform managers about forage availability, plant community composition and structure, and risk of runoff and erosion.

The line-point intercept method, in which cover is recorded at a point every $1 \mathrm{~m}$ along a tape, is a robust and commonly used method for measuring plant and ground cover. ${ }^{5}$ The "stick point" method we described was adapted from the line-point intercept method. Instead of recording cover every $1 \mathrm{~m}$ along a tape, the data collector instead records cover at five marked points (20 cm apart) along the 1-m-long stick (Fig. 3A). Users observe cover at each mark along one edge of the stick so that cover data are effectively collected at a series of zero-dimensional points. This is repeated every $5 \mathrm{~m}$ along the transect, for a total of 25 points on each transect or 100 points for each site.

In its simplest form, the stick-point method and data sheet can be used to measure plant cover for several key functional groups (e.g., plant bases, grass and forb canopies, shrub canopies, and tree canopies) as well as the percent of the ground that is covered by lichens and biological crusts, litter, and rock. Data are recorded by circling icons or by making a mark on a drawing of the stick (Fig. 3B). The data collector can gather additional data using various markings. For example, cover of "desirable" plants can be indicated by circling the appropriate plant icon, while cover of "undesirable" plants can be indicated by marking an "X" over the plant icon. Similarly, data on cover of species of particular interest (e.g., invasive or alien species) can be collected by making a 


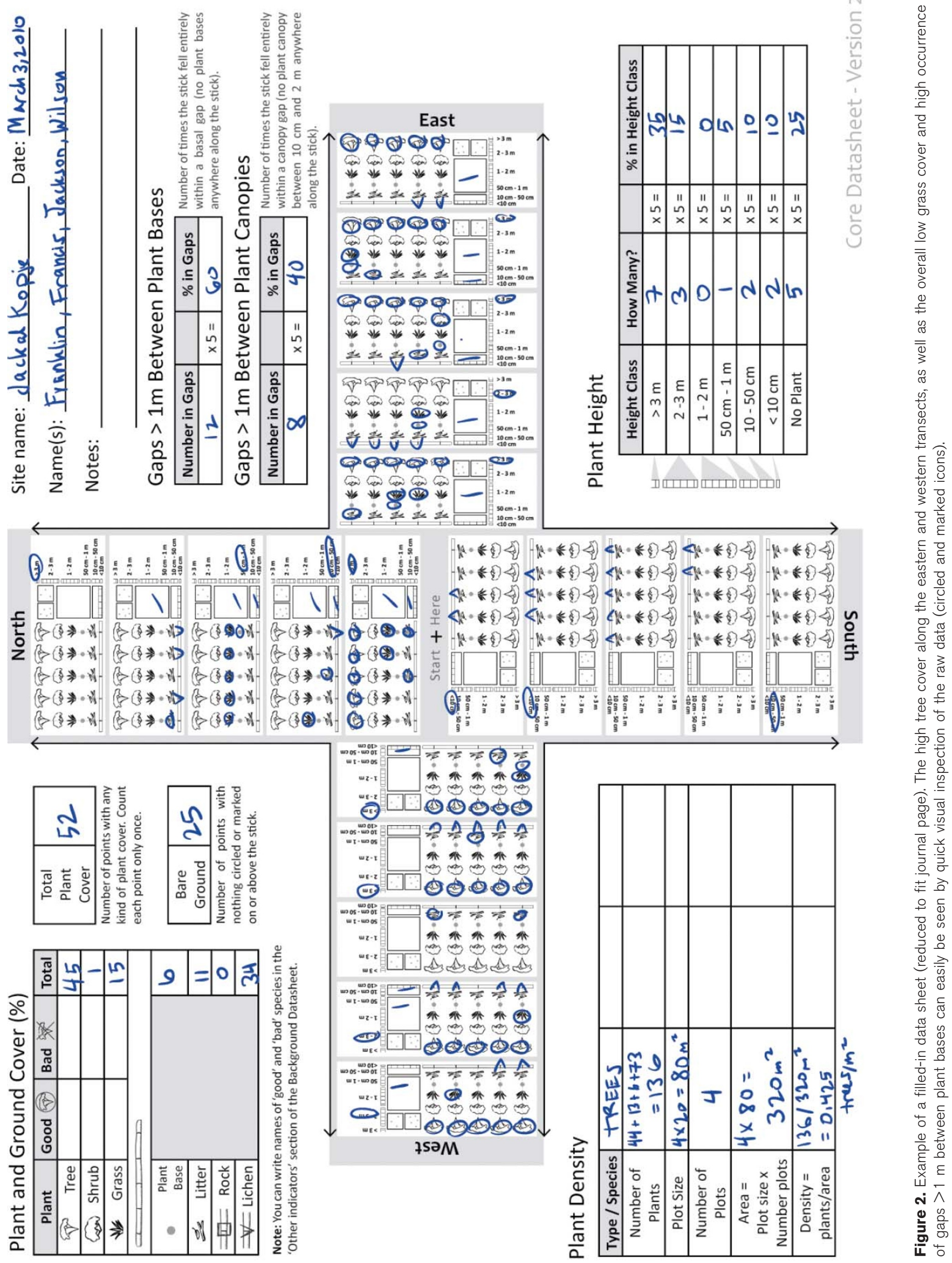




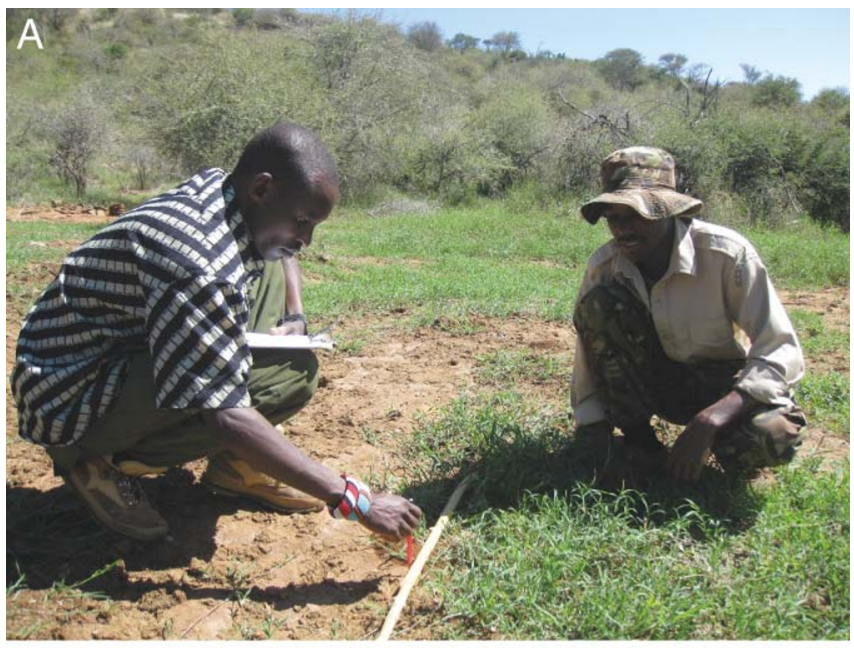

B

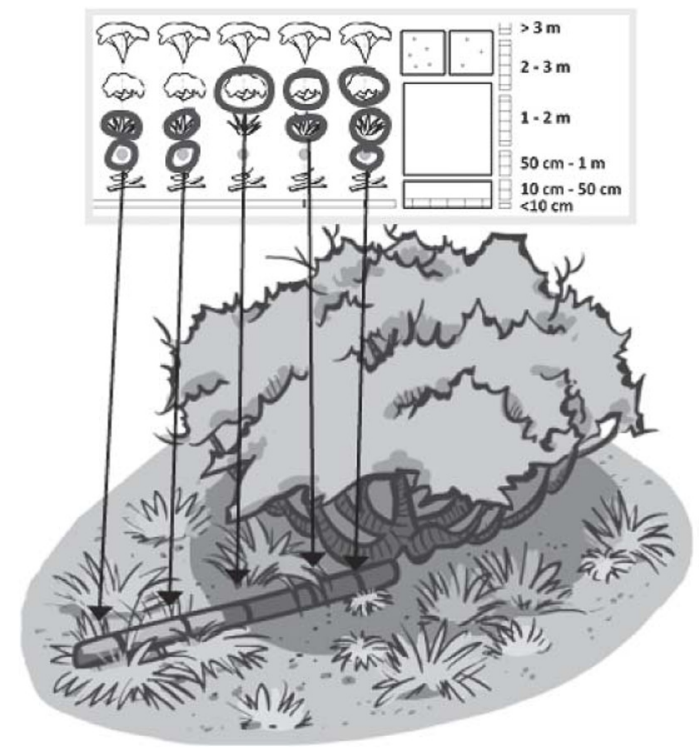

Figure 3. Plant and ground cover data are recorded for each of five stick points.

unique marking (e.g., filled circle or box) over the plant icon. Because cover is measured at a total of 100 points per site, the percent cover of each plant functional type can be calculated by simply counting the number of icons that were marked at that site. Total plant cover and total bare ground are calculated by counting the number of stick points where at least one type of plant or no ground cover was recorded, respectively.

\section{Method 2: Gaps > X cm Between Plants}

The spatial arrangement of plants at a site-in addition to the percent of the ground that is covered by plants-is an important determinant of erosion potential. ${ }^{14}$ Generally, sites that have larger gaps between plant bases are less effective at slowing the flow of water over the soil surface than sites that have smaller gaps between plant bases. Similarly, sites that have larger gaps between plant canopies, and less vertical canopy structure, are less effective at slowing the movement of wind over the soil surface. In addition, the spatial arrangement of the vegetation can be an important determinant of habitat quality for wildlife. Different species have different requirements in terms of horizontal vegetation structure (e.g., continuous rather than patchy grass cover for many small mammals) and vertical vegetation structure (e.g., perches for birds vs. more open habitat for many ungulates).

Horizontal vegetation structure can be measured using the "stick-gap" method—a modified version of the "gapintercept" method. The gap-intercept method is typically used to measure gaps (both between plant bases and canopies) greater than some minimum threshold along a transect. ${ }^{5}$ In the stick-gap method, the data collector records the number of times that a segment of the stick of a certain length (usually measured in centimeters) falls within a gap between plant bases or a gap between plant canopies (Fig. 4A). The presence of any plant base or plant canopy "breaking the gap" is recorded on the data sheet by drawing a line through an empty box (literally breaking the gap; Fig. 4B) or simply by writing "NB" for "no base" or "NC" for "no canopy" in the same box. This is recorded at each of the five locations along each transect where the stick is laid down, for a total of 20 stick locations. The number of sticks for which the segment length falls entirely within a gap is then multiplied by five to get the percentage of the landscape that falls in gaps larger than the segment. This approach is similar to the "step-gap" method..$^{5}$

In our initial trials in degraded, spatially heterogeneous landscapes of Kenya and Ethiopia, we used a 100-cm (entire length of the stick) gap length. While this size of gap may be appropriate for degraded landscapes that have lost large amounts of connectivity among vegetated patches, ${ }^{14}$ this is clearly too large a gap for other, less degraded or less patchy landscapes (e.g., temperate grasslands); for these areas, a shorter minimum length would need to be specified. Due to the fact that stick locations are chosen randomly, we recommend a minimum stick-segment length approximately half the minimum gap size of interest.

\section{Method 3: Plant Height}

Vertical vegetation structure can be monitored by capturing data on maximum plant height at each stick location. Data collectors outline a plot $1 \times 1 \mathrm{~m}$ in front of the stick at each stick-location (using a second stick, if necessary, to outline the plot) and estimate the height of the tallest plant part directly above that $1 \times 1 \mathrm{~m}$ plot (Fig. 5A). They then categorize the tallest plant part as being $<10 \mathrm{~cm}$ tall, 10 to 50 $\mathrm{cm}, 50 \mathrm{~cm}$ to $1 \mathrm{~m}, 1$ to $2 \mathrm{~m}, 2$ to $3 \mathrm{~m}$, and $>3 \mathrm{~m}$ tall, and they circle the relevant category on the data sheet (Fig. 5B). The sticks can be used to help estimate plant height, because they are each $1 \mathrm{~m}$ long and have markings at both the $10-\mathrm{cm}$ and $50-\mathrm{cm}$ mark. Because plant height is sampled at 20 locations across a site, the number of samples in each height class is multiplied by five to get the percentage of the landscape where the tallest plant part is in each height category. 


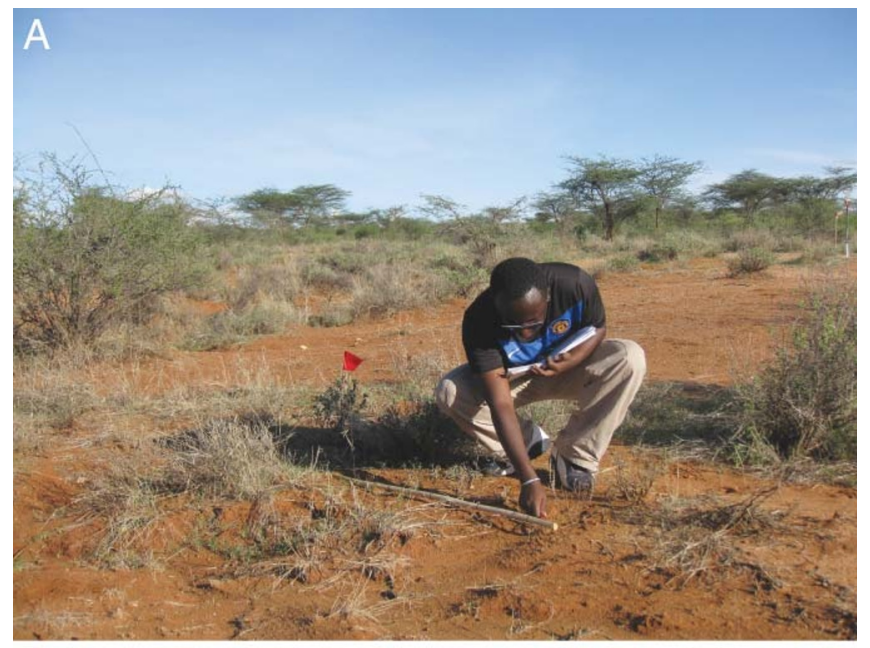

B

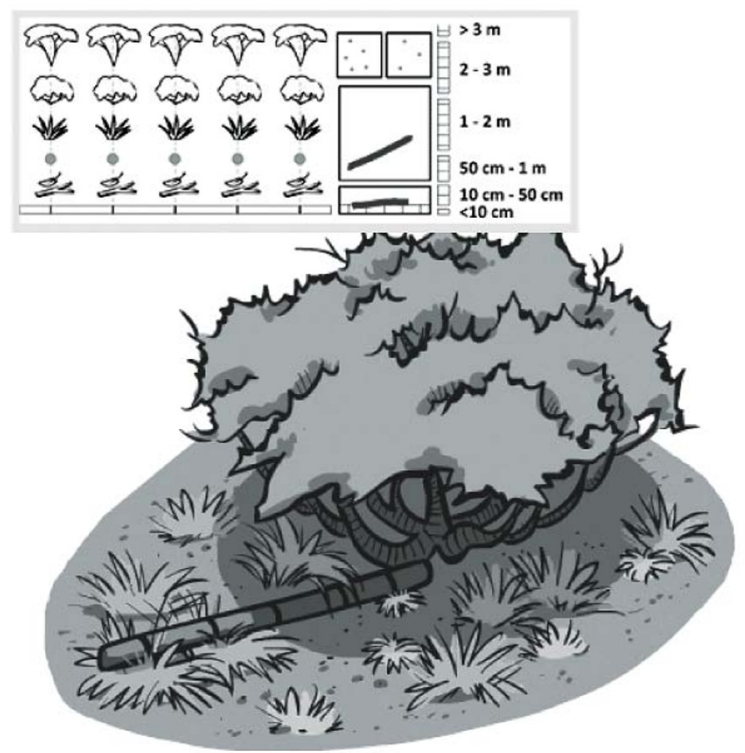

Figure 4. Basal and canopy gap boxes are marked when plant bases and plant canopy, respectively, are present anywhere along the 1-m stick, breaking the gap (no gap $>1 \mathrm{~m}$ between plant bases and canopies).

\section{Method 4: Plant Density}

Plant density data are an important complement to plant cover data, particularly for plants that have low cover but are ecologically important (e.g., seedlings of invading species). Plant density (number of plants per unit area) can provide an early indicator of future changes in plant cover, forage quality, and habitat structure.

Plant density needs to be measured on a spatial scale that is appropriate for the plants of interest. We suggest three possible spatial scales, each of which can be integrated with the above three methods. At the smallest spatial scale (most appropriate for small plants and seedlings that are relatively common), the data collector can count the number of plants present in a $1 \times 1 \mathrm{~m}$ plot that is delineated at each stick location. The total number of plants is divided by $20 \mathrm{~m}^{2}$ to get density per square meter.

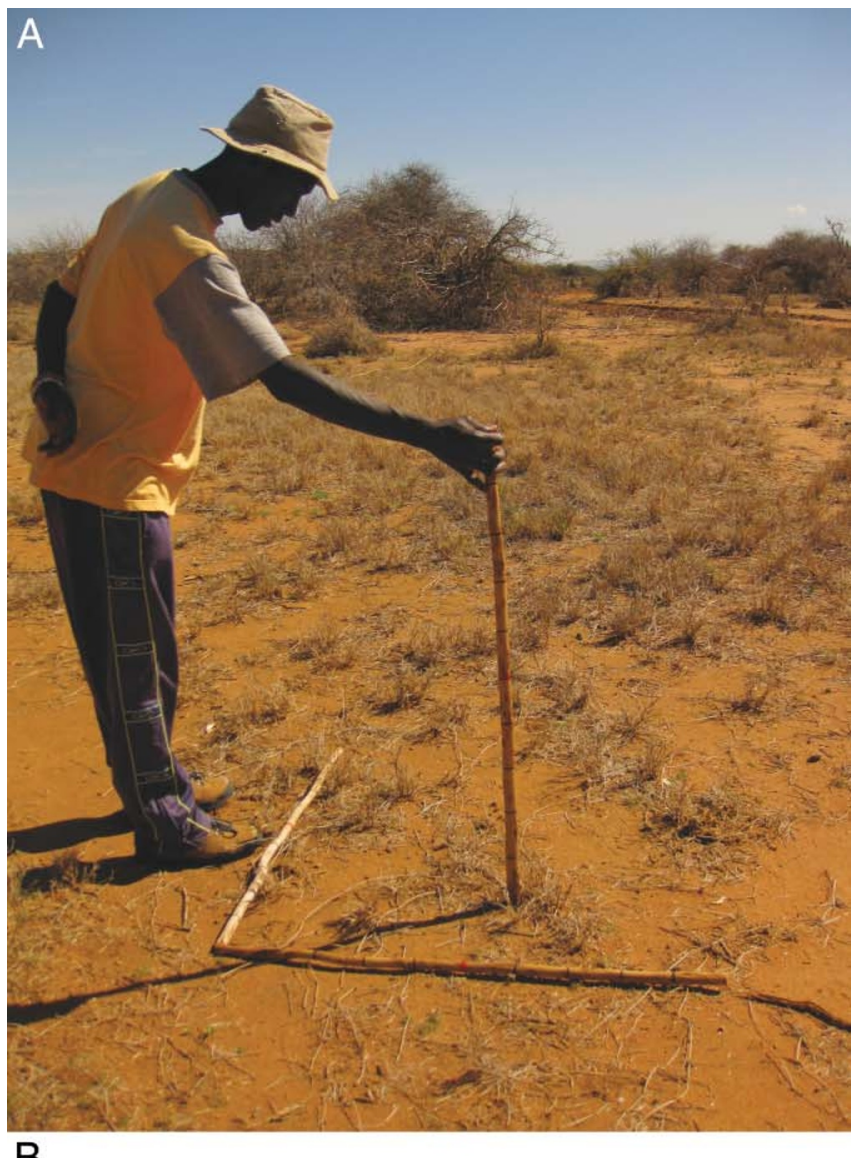

B
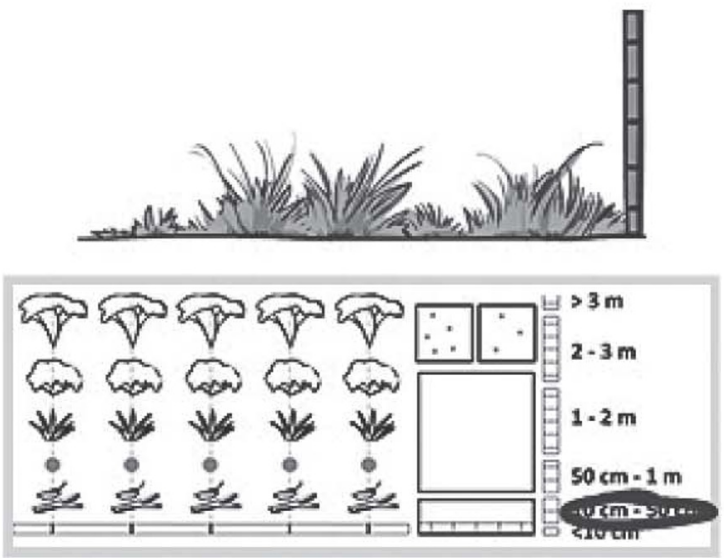

Figure 5. Plant height data are recorded by circling the correct size class for the tallest plant part above a $1 \times 1 \mathrm{~m}$ box at each sample location.

At a more intermediate spatial scale (most appropriate for shrubs and small trees), the data collector can measure tree density in four belt transects (one for each direction from the site's center point). The stick can be used to help determine whether plants are rooted within the belt (Fig. 6A). In field trials, we found it most efficient for the data collector to turn around at the end of each transect (after measuring plant cover, gaps between plants, and plant height along the transect) and count the plants within the belt transect as 


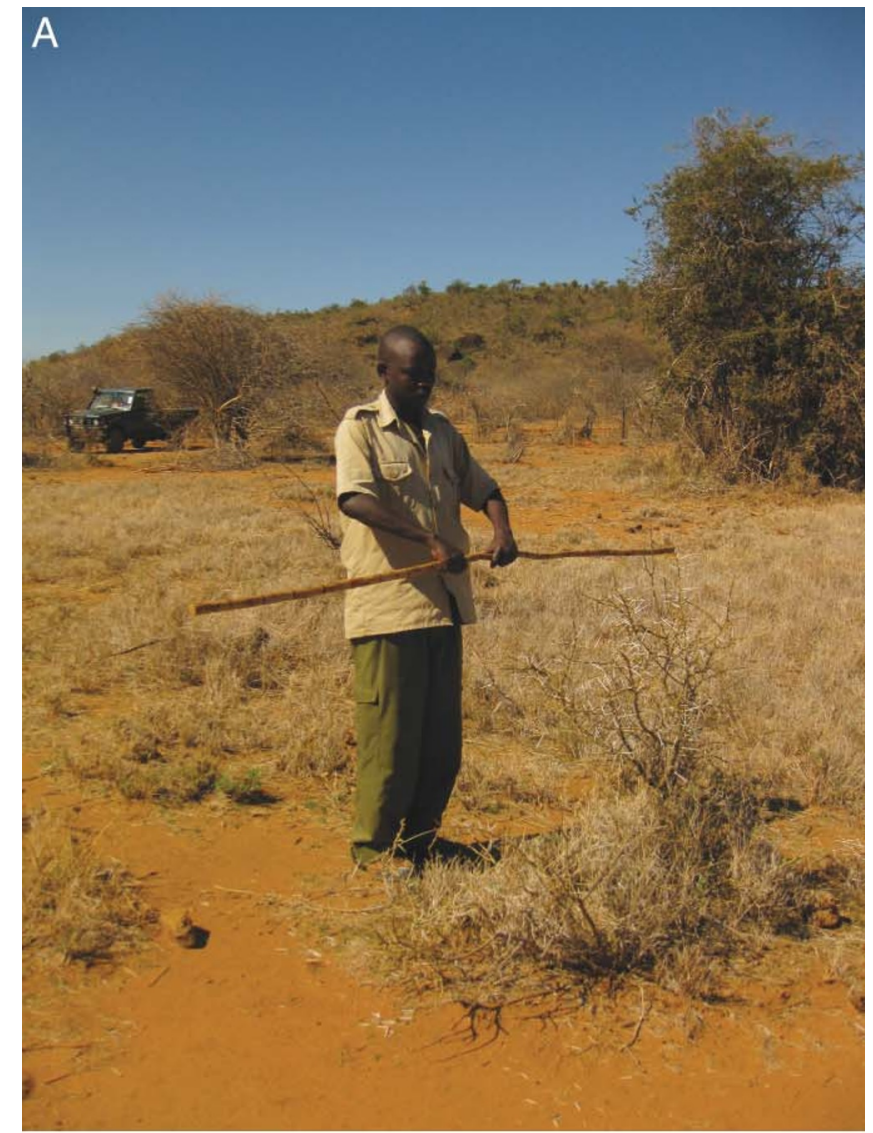

B

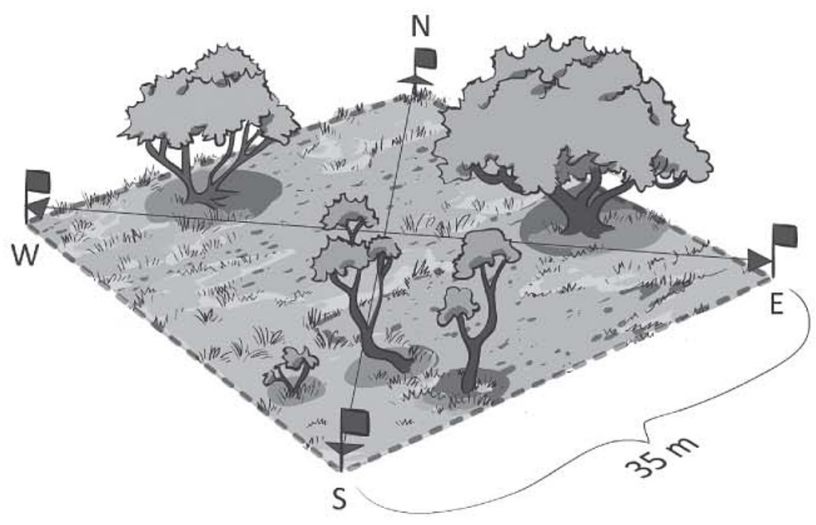

Figure 6. Plant density data are collected (A) along four 20-m-belt transects, $(\mathbf{B})$ in a $35 \times 35 \mathrm{~m}$ plot formed by connecting the ends of the four $25-\mathrm{m}$ transects, or in a $1 \times 1 \mathrm{~m}$ box at each sample location (not pictured).

he/she returned to the center point. To avoid overlap near the center point, we recommend counting plants along a 20-m-long transect (avoiding the $5 \mathrm{~m}$ closest to the center of the site). For belts that are $4 \mathrm{~m}$ wide $(2 \mathrm{~m}$ on either side of the transect), plant density per square meter can be calculated by dividing the total number of plants by $320 \mathrm{~m}^{2}(20 \mathrm{~m} \times 4 \mathrm{~m}$ $\times 4$ transects).

Finally, at the largest spatial scale, plant density can be measured by counting the number of plants in a single, large plot. This scale is most appropriate for large trees or rare plants. A single plot (approximately $35 \mathrm{~m}$ on each side, or $\times 1,250 \mathrm{~m}^{2}$ in area) can be delineated using the ends of each of the four transects as the corners (Fig. 6B). Plant density is then calculated as the number of plants divided by $1,250 \mathrm{~m}^{2}$.

These options for measuring plant density provide a flexible system that covers a variety of situations encountered in arid and semiarid rangelands. Although deciding which option is most appropriate may be difficult, each method is simple to execute.

\section{Analysis and Interpretation}

For any monitoring program, the data collected must be analyzed and interpreted within the context of the goals that land managers have set for their management and monitoring. For example, decisions about which data to collect or which monitoring sites to treat as replicates will depend on what the manager wants to learn from his or her monitoring and how this knowledge will inform management. We discuss these issues in greater detail in the manual, ${ }^{3}$ which, although aimed at an East African audience, presents principles applicable to most rangelands around the world, regardless of which data collection methods are used. The methods introduced here, however, may facilitate analysis and interpretation through their simplicity since they capture data on a few important indicators of ecosystem function and these indicators can be calculated rapidly. Managers can thus quickly examine trends in indicators over time or space.

\section{Strengths and Limitations of These Methods Strengths}

The strengths of this approach to rangeland monitoring lie largely in its simplicity and ease of use. In the process of testing these methods, we found that people could learn to use them correctly within 1-4 hours, depending on their level of literacy and experience. The graphical arrangement of the data sheet also enabled users to quickly and accurately record the data. Importantly, these methods do not require any equipment other than a stick - a tool that is readily available and appeals to users in its simplicity.

The methods are also quick to use. In field trials, we found that plant cover data could be collected in 15-20 minutes (about one-fifth of the time required to collect line-point intercept data along the same four transects), and data for all four methods could be collected in about 45 minutes. Data summarization is similarly quick and easy to learn. Users were able to calculate a variety of indicators from their data in about 10 minutes. Users appreciated that data could be summarized on-site, immediately after being collected, on a single sheet of paper. The graphical data-collection system also enabled users to visualize the data as they calculated indicators from it.

In our experience, the simplicity and ease of use of these methods generally leaves potential users feeling positive toward monitoring and empowered to conduct their own data collection. The feeling that monitoring is feasible, 
rather than technical and time-consuming, will, we hope, lead to more widespread implementation and lasting use of these monitoring methods.

\section{Limitations and Areas for Further Research}

The main limitation to these methods is that they compromise some precision for the sake of simplicity and ease of use. For example, the "stick point" method is not suitable for collecting plant cover data for many different species; rather, it focuses primarily on plant functional groups and key species of particular interest. Similarly, the plant height method provides a very simple indicator of vertical vegetation structure that may be sufficient to indicate broad changes in vegetation structure but may not be sufficient for detailed habitat modeling for wildlife. The plant density methods in particular may be sensitive to user errors such as imprecise transect lengths. As discussed above, the stick-gap approach may not capture important information about small gaps between plants if the stick segment length being used is not appropriate for the ecosystem. It also limits interpretation to a single gap length. Further research is needed to establish the minimum gap length that is suitable for different ecosystems.

Within-site sample sizes for each method will also need to be tested to verify that they are sufficient to capture average site characteristics-and provide enough power to detect change-for a variety of landscapes. Currently, cover, gap, and height data are collected at 20 stick locations for each site. This has proven to be a tractable number for data collection and indicator calculation (requiring only counting or counting and multiplying by five). However, $5 \%$ is the minimum difference that can be observed for vegetation structure or percentage of the landscape in gaps $>X \mathrm{~cm}$. Thus the effective minimum change that could be detected across sample dates would be $10 \%$ or more. Further testing is needed to establish whether 20 sample points are sufficient to detect small but ecologically meaningful changes in the landscape.

These methods do not rely on fixed transects and tapes, making them substantially faster and easier to collect data. However, this may reduce the repeatability of data collection. Although the central point of each site is fixed, the exact transect walked and stick points sampled may vary from user to user or from year to year even with the same user. This may introduce greater variance in the data, reducing the user's ability to detect small changes in indicators of ecosystem function. Further research is needed to determine the sensitivity of this approach to different users.

\section{Potential Application in Rangelands Around the World}

The basic indicators generated by the methods we present here are compatible with those being used in many areas throughout the world to capture changes in plant community cover, composition and structure, and in basic ecosystem processes, including runoff and erosion. While these methods cannot be used to generate as many indicators, or at the same level of precision as more traditional, tape- and quadratbased techniques, the data should be sufficient to address most on-farm or on-ranch monitoring objectives.

Some local adaptations may be necessary to use this approach to monitoring in different parts of the world. Even within eastern Africa, we found that it was rarely necessary to apply all four methods, but that supplementary monitoring (such as wildlife censuses) were sometimes advisabledepending on the local management questions and objectives. In grassland regions of the world, methods such as vertical plant structure or plant density may be less relevant. At the savanna-woodland transition, measuring vertical structure may be impractical. Finally, adapting the data collection tool (i.e., stick) to suit the local cultural context may help to make the method more appealing to potential users.

By designing a set of methods that are quick and easy to use, our goal was to make rangeland monitoring more accessible and widely practiced by a variety of land managers. Monitoring of long-term changes in rangeland function using standardized, quantitative methods is critical to documenting land degradation around the world - and bringing attention to this degradation will, we hope, assist in arresting it before it worsens.

\section{Acknowledgments}

We thank the Enhanced Livelihoods in the Mandera Triangle program, USAID-East Africa, USAID-Kenya, Princeton University, the U.S. Department of AgricultureAgricultural Research Service, the Denver Zoological Foundation, CARE International, and the U.S. Geological Survey for supporting the development and testing of these monitoring methods. We also thank all of the workshop participants in Kenya and Ethiopia who field tested and helped improve the methods. We are most grateful to Margaret Kinnaird, Jeffrey Worden, Dickson ole Kaelo, Dominic Lesimirdana, Charles Hopkins, Aliyu Mustefa, and Alfenur Abu for their critical assistance at various stages in the development of these methods. This manuscript was improved by comments from David Pyke, Mike Duniway, Jason Karl, and two anonymous reviewers. Finally we thank Heather Larkin for all illustrations and graphics.

\section{References}

1. Herrick, J. E., B. T. Bestelmeyer, S. Archer, A. Tugel, AND J. R. BRown. 2006. An integrated framework for sciencebased arid land management. Journal of Arid Environments 65:319-335.

2. Herrick, J. E., V. C. Lessard, K. E. Spaeth, P. L. Shaver, R. S. Dayton, D. A. Pyke, L. Jolley, and J. J. Goebel. 2010. National ecosystem assessments supported by local and scientific knowledge. Frontiers in Ecology and the Environment 8:403-408. DOI: $10.1890 / 100017$.

3. Riginos, C., And J. E. Herrick. 2010. Monitoring rangeland health: a guide for pastoralists and other land managers in eastern 
Africa, version ii. Nairobi, Kenya: ELMT-USAID/East Africa. $100 \mathrm{p}$.

4. Herlocker, D. 1995. Range resource monitoring: field and office guidelines. Range management handbook of kenya, volume III, 10. Nariobi, Kenya: MALDM/GTZ Range Management Handbook Project. 60 p.

5. Herrick, J. E., J. W. Van Zee, K. M. Havstad, L. M. Burkett, and W. G. Whitford. 2005. Monitoring manual for grassland, shrubland, and savanna ecosystems. Vol. I. USDAARS Jornada Experimental Range, Las Cruces, NM, USA: University of Arizona Press. 36 p.

6. Tongway, D. J., And J. A. Ludwig. 2010. Restoring disturbed landscapes: putting principles into practice. Washington, DC, USA: Island Press. 216 p.

7. Berkes, F., J. Colding, and C. Folke. 2000. Rediscovery of traditional ecological knowledge as adaptive management. Ecological Applications 10:1251-1262.

8. Fernàndez-Gimenez, M. A. 2000. The role of Mongolian nomadic pastoralists' ecological knowledge in rangeland management. Ecological Applications 5:1318-1326.

9. Reed, M. S., And A. J. Dougill. 2002. Participatory selection process for indicators of rangeland condition in the Kalahari. The Geographical Journal 168:224-234.

10. Rова, H. G., ANd G. Ова. 2009. Efficacy of integrating herder knowledge and ecological methods for monitoring rangeland degradation in northern Kenya. Human Ecology 37:589-612.

11. King, J., G. Parker, and D. Lesimirdana. 2009. Developing participatory rangeland monitoring and management. Nayuki, Kenya: Report by Northern Rangelands Trust and Marwell Wildlife. 7 p.
12. Ова, G. 1998. Assessment of indigenous range knowledge of the Boran pastoralists of southern Ethiopia. Yabelo, Ethiopia: Report commissioned by the GTZ-Boran Lowland Pastoral Development Program in collaboration with the Oromia Regional Bureau of Agricultural Development. 136 p.

13. Pyke, D. A., J. E. Herrick, P. Shaver, and M. Pellant. 2002. Rangeland health attributes and indicators for qualitative assessment. Journal of Rangeland Management 55:584-597.

14. Okin, G. S., A. J. Parsons, J. Wainwright, J. E. Herrick, B. T. Bestelmeyer, D. C. Peters, and E. J. Fredierckson. 2009. Do changes in connectivity explain desertification? BioScience 59:237-244.

Authors are Postdoctoral Fellow, Dept of Ecology and Evolutionary Biology, Princeton University, Princeton, NJ 08544, USA, and Mpala Research Centre, P.O. Box 555, Nanyuki, 10400, Kenya, criginos@gmail.com (Rigino); Research Soil Scientist, US Dept of Agriculture-Agricultural Research Service, Jornada Experimental Range, Las Cruces, NM 88003, USA (Herrick); Kenya Program Director, Dept of Conservation Biology, Denver Zoological Foundation, Denver, CO 80205, USA, and Mpala Research Centre, Nanyuki, 10400, Kenya (Sundaresan); Chief Operating Officer, Mara North Conservancy, P.O. Box 1081-00517, Nairobi, Kenya (Farley); and Research Ecologist, US Geological Survey, Southwest Biological Science Center, 2290 S. Resource Blvd, Moab, UT 84532, USA (Belnap). 